\title{
OPTIMIZATION OF GEOMETRIC PARAMETERS OF A RIBBON IMPELLER
}

\author{
Czesław Kuncewicz*, Jacek Stelmach \\ Łódź University of Technology, Faculty of Process and Environmental Engineering, ul. Wólczańska \\ 213, 90-924 Łódź, Poland
}

\begin{abstract}
Geometric parameters of a ribbon impeller were optimized on the basis of numerical calculations obtained from the solution of our own $3 \mathrm{D} / 2 \mathrm{D}$ hybrid model. The optimization was made taking into account mixing power and homogenization time for ribbon impellers with a different number of ribbons and width operating in a laminar motion for Newtonian fluid. Due to minimum mixing energy required to stir a unit volume of liquid the most efficient impeller appeared to be that with one ribbon of width equal to 0.1 to 0.15 of the mixing vessel diameter. Impellers with more than one ribbon needed much higher mixing power but did not increase significantly secondary circulation in the vessel. These impellers increased first of all primary circulation, i.e. they increased only circular motion of liquid in the vessel.
\end{abstract}

Keywords: mixing, laminar motion, ribbon impellers, optimization

\section{INTRODUCTION}

Mixing in the liquid phase is very often used in various technological processes, and in many cases efficiency of the whole process depends on mixing intensity. This refers, for example, to fast chemical reactions controlled in the reactor by the rate of mixing in a micro scale. A similar problem arises in the mixing of highly viscous liquids, e.g. during polymerization. In general, for mixing highly viscous liquids: anchor, ribbon or screw impellers are used. The first of these works well in the case when there is a need of a jacketed heat exchange on the mixing reactor wall. The paddle of an anchor operating near the tank wall disrupts thermal boundary layer thus increasing the intensity of heat exchange on its wall. However, this type of impeller produces a very weak radial-axial circulation which usually results in poor mixing of the liquid in the whole volume of the vessel. Ribbon impellers do not have this disadvantage. Structurally they are more difficult to manufacture but due to relative inclination of the rotating ribbon the impeller pumps liquid up or down thereby increasing significantly the radial-axial circulation and as a result decreasing the mixing time. Therefore, this type of impellers is widely applied when you need to mix highly viscous liquids (Delaplace et. al., 2000; Dalaplace et. al., 2006; Kuncewicz, 2012; Robinson and Cleary, 2012).

Due to the extensive use of ribbon impellers in industrial practice they have been the subject of frequent research. Curran (Curran et. al., 2000) studied experimentally the hydrodynamics and circulation time in a reactor with a simple and double helical ribbon impeller in case of yield stress fluids. They revealed the independency of the dimensionless circulation time of the fluid rheology and pumping direction in case of the double helical ribbon. In contrast, the simple ribbon presented high values of dimensionless circulation time for the highest viscosity fluid. Robinson and Cleary (Robinson and Cleary, 2012) have studied the mixing flow within three variants of the helical ribbon impellers, 
a single helical ribbon impeller, a double helical ribbon and a single helical ribbon combined with a central screw. They proved that the mixing rate is better while adding an extra ribbon compared to the single ribbon results, while, the addition of a central screw leads to a creation of a low mixing zone surrounding the screw. However, this work did not specify the mixing efficiency for this type of stirrer.

Many similar papers have been written since and they concern the hydrodynamics of the mixer or mixing times or both parameters simultaneously. However, they do not include studies on the circulation times inside the mixer and the relationship between mixing time and circulation time. The presented work complements this gap.

Over the last two decades there has been a growing number of works based on numerical calculations using CFD techniques (Ameur et.al., 2015; Ameur, 2017; Anne-Archard et. al., 2006) or experimental work using modern measurement techniques (Takahashi et al., 2015; Wang et al., 2012).

Another area of interest of ribbon impellers is the food industry. Especially when you should reach concentration of solid phase of more than 50\% (Hou, 2016; Zhang, 2014). A high value of secondary circulation in the r-z plane in the mixer even at low rotational speeds of the stirrer effectively mixes the two phases without destroying the solid. So, the helical ribbon impeller was successfully introduced into pretreatment reactors for the purpose of intensified mixing of corn stover with liquid dilute acid solution and hot steam (He et.al., 2014a; He et.al., 2014b) or into bioreactors for enzymatic hydrolysis and fermentation (Liu et al., 2012; Zhang et al., 2010; Zhao et al., 2013). The results showed that the bioconversion yield and pretreatment efficiency was significantly improved. Wu (2012) made a comparison of six types of impellers for mixing high-solids anaerobic digestion systems and found the helical ribbon impeller was the most effective solution.

From the viewpoint of obtaining a homogeneous mixture in the entire volume of the vessel, we often employ two basic concepts: the homogenization time $\tau_{m}$ and circulation time $\tau_{c}$. Both concepts refer to mixing in the entire tank volume and despite not very precise definition they have been used for a long time. By definition (Stręk, 1981) the time of homogenization $\tau_{m}$ (or mixing time) is the time needed by the system to reach high enough homogeneity required by process conditions. The time of circulation $\tau_{c}$ is the average time which every element of the liquid requires for making one full circulation loop in the radial-axial plane in the vessel. As has been mentioned, both definitions are unclear. Hence, results obtained by different authors who additionally use different measuring techniques can differ appreciably. The values of $\tau_{m}$ and $\tau_{c}$ are directly related to secondary circulation in the tank, i.e. to the volumetric flow rate of liquid $V_{s}\left[\mathrm{~m}^{3} / \mathrm{s}\right]$ in the r-z plane. The higher the value of $V_{s}$, the shorter the time of homogenization $\tau_{m}$. To practically determine the time of homogenization various measuring techniques are used (see legend to Table 1).

Table 1 shows experimental data available in the literature regarding the time of homogenization $\tau_{m}$, circulation $\tau_{c}$ and power of mixing in the form of product $\mathrm{Po} \cdot \mathrm{Re}=A$. The values of $\tau_{m}$ and $\tau_{c}$ are given in the form of dimensionless products $N \tau_{m}$ and $N \tau_{c}$. Table 1 gives also geometry of the ribbon impellervessel system and measuring method which was used to determine the time of homogenization.

Data in Table 1 refer only to ribbon impellers because according to many authors (Bakker and Gates, 1995; Coyle et al., 1970; Rieger et al., 1986; Shiue and Wong, 1984) this type of impeller is most suitable for mixing liquids with high viscosity.

It can be easily seen from Table 1 that mixing times are always several times greater than the circulation times (Carreau et al., 1976; Guerin et al., 1984; Takahashi et al., 1989; Takahashi et al., 1994). Therefore, an attempt can be made to find a relationship between the values of $\tau_{m}$ and $\tau_{c}$ for the same type of impeller irrespective of its geometric parameters. In other words, it is possible to determine the number of full circulation loops which should be made by every element of liquid in the vessel to make the liquid obtain an appropriate degree of homogeneity. Figure 1 shows selected data 
from Table 1 concerning the values of $\tau_{m}$ and $\tau_{c}$ for ribbon impellers with different geometric parameters.

Table 1. The time of homogenization and circulation for ribbon impellers available in the literature

\begin{tabular}{|c|c|c|c|c|c|c|c|c|c|}
\hline Authors & $d(\mathrm{~m})$ & $D / d$ & $w / d$ & $p / d$ & $H / d$ & $N_{R}$ & $A$ & $N \tau_{m}$ & $N \tau_{c}$ \\
\hline Carreau et al. (1976) & $\begin{array}{l}0.130 \\
0.130 \\
0.130 \\
\end{array}$ & $\begin{array}{l}1.110 \\
1.110 \\
1.110\end{array}$ & $\begin{array}{l}0.097 \\
0.097 \\
0.195 \\
\end{array}$ & $\begin{array}{l}0.719 \\
1.048 \\
0.707\end{array}$ & $\begin{array}{l}1.11 \\
1.11 \\
1.11 \\
\end{array}$ & $\begin{array}{l}2 \\
2 \\
2 \\
\end{array}$ & $\begin{array}{l}355.0 \\
234.0 \\
314.0 \\
\end{array}$ & $\begin{array}{l}45^{1)} \\
51^{1)} \\
25^{1)} \\
\end{array}$ & $\begin{array}{c}13.2^{\text {a) }} \\
13.1^{\text {a) }} \\
7.1^{\text {a) }}\end{array}$ \\
\hline Ulbrecht and Carreau (1985) & $\begin{array}{l}0.105 \\
0.130 \\
0222 \\
\end{array}$ & $\begin{array}{l}1.370 \\
1.110 \\
1.110 \\
\end{array}$ & $\begin{array}{l}0.121 \\
0.097 \\
0.099 \\
\end{array}$ & $\begin{array}{l}0.848 \\
0.695 \\
0.690 \\
\end{array}$ & $\begin{array}{l}1.37 \\
1.11 \\
1.12 \\
\end{array}$ & $\begin{array}{l}2 \\
1 \\
2 \\
\end{array}$ & $\begin{array}{c}199.0 \\
160.0 \\
-\quad \\
\end{array}$ & $\begin{array}{c}55^{1)} \\
61.0^{1)} \\
- \\
\end{array}$ & $\begin{array}{c}15^{\mathrm{a})} \\
21.8^{\mathrm{a})} \\
- \\
\end{array}$ \\
\hline Coyle et al. (1970) & 0.432 & 1.059 & 0.083 & 0.500 & 1.06 & 1 & - & $63.0^{\text {a) }}$ & $20.0^{\mathrm{a})}$ \\
\hline Gelus (1979) & - & $\begin{array}{l}1.111 \\
1.111\end{array}$ & $\begin{array}{l}0.111 \\
0.111\end{array}$ & $\begin{array}{l}1.000 \\
1.000 \\
\end{array}$ & $\begin{array}{l}1.00 \\
1.00\end{array}$ & $\begin{array}{l}2 \\
2 \\
\end{array}$ & $\begin{array}{l}265 \\
265\end{array}$ & $\begin{array}{c}100^{8)} \\
1301^{\text {a) }}\end{array}$ & $\begin{array}{c}9.5^{\mathrm{b})} \\
12^{\mathrm{a})}\end{array}$ \\
\hline Guerin et al. (1984) & $\begin{array}{l}0.130 \\
0.130 \\
0.130 \\
0.130 \\
0.220\end{array}$ & $\begin{array}{l}1.108 \\
1.108 \\
1.108 \\
1.108 \\
1.127\end{array}$ & $\begin{array}{l}0.100 \\
0.100 \\
0.200 \\
0.100 \\
0.100\end{array}$ & $\begin{array}{l}0.720 \\
1.050 \\
0.710 \\
0.700 \\
0.700\end{array}$ & $\begin{array}{l}1.11 \\
1.11 \\
1.11 \\
1.11 \\
1.11\end{array}$ & $\begin{array}{l}2 \\
2 \\
2 \\
1 \\
2\end{array}$ & $\begin{array}{l}- \\
- \\
- \\
-\end{array}$ & $\begin{array}{l}45.0^{1)} \\
49.0^{1)} \\
22.0^{1)} \\
53.0^{1)} \\
45.0^{1)}\end{array}$ & $\begin{array}{l}12.9^{\mathrm{a})} \\
12.3^{\mathrm{a}} \\
11.0^{\mathrm{a}} \\
17.7^{\mathrm{a})} \\
17.3^{\mathrm{a}}\end{array}$ \\
\hline Nagata et al. (1956) & $\begin{array}{l}0.094 \\
0.094 \\
0.191 \\
0.285 \\
\end{array}$ & $\begin{array}{l}1.064 \\
1.064 \\
1.053 \\
1.053 \\
\end{array}$ & $\begin{array}{l}0.117 \\
0.117 \\
0.105 \\
0.105 \\
\end{array}$ & $\begin{array}{l}0.745 \\
1.112 \\
1.000 \\
1.000 \\
\end{array}$ & $\begin{array}{l}1.06 \\
1.06 \\
1.05 \\
1.01 \\
\end{array}$ & $\begin{array}{l}1 \\
1 \\
2 \\
2 \\
\end{array}$ & $\begin{array}{l}250.0 \\
192.0 \\
330.0 \\
302.0 \\
\end{array}$ & $\begin{array}{l}33.0^{1)} \\
33.0^{1)} \\
33.0^{1)} \\
33.0^{1)}\end{array}$ & $\begin{array}{c}11.0^{\text {a) }} \\
11.7^{\text {a) }} \\
- \\
12.7^{\text {a) }}\end{array}$ \\
\hline Soliman (1985) & 0.602 & 1.053 & 0.100 & 1.000 & 1.01 & 2 & 315 & $49.0^{1)}$ & $12.8^{c)}$ \\
\hline Takahashi et al. $(1982,1988)$ & $\begin{array}{l}0.096 \\
0.088 \\
0.082 \\
0.096 \\
0.089 \\
0.083 \\
0.090 \\
0.090 \\
0.089 \\
0.088 \\
0.090 \\
0.090 \\
0.090 \\
0.091\end{array}$ & $\begin{array}{l}1.040 \\
1.138 \\
1.222 \\
1.040 \\
1.126 \\
1.209 \\
1.110 \\
1.115 \\
1.126 \\
1.136 \\
1.115 \\
1.114 \\
1.109 \\
1.098\end{array}$ & $\begin{array}{l}0.104 \\
0.114 \\
0.122 \\
0104 \\
0.113 \\
0.121 \\
0.111 \\
0.111 \\
0.113 \\
0.114 \\
0.084 \\
0.140 \\
0.169 \\
0.220\end{array}$ & $\begin{array}{l}0.937 \\
1.025 \\
1.101 \\
0.937 \\
1.015 \\
1.089 \\
0.665 \\
0.502 \\
1.351 \\
2.045 \\
1.004 \\
1.003 \\
0.999 \\
0.989\end{array}$ & $\begin{array}{l}1.04 \\
1.14 \\
1.22 \\
1.04 \\
1.13 \\
1.21 \\
1.11 \\
1.11 \\
1.13 \\
1.14 \\
1.11 \\
1.11 \\
1.11 \\
1.10\end{array}$ & $\begin{array}{l}1 \\
1 \\
1 \\
2 \\
2 \\
2 \\
2 \\
2 \\
2 \\
2 \\
2 \\
2 \\
2 \\
2 \\
\end{array}$ & $\begin{array}{l}- \\
- \\
- \\
- \\
- \\
- \\
- \\
- \\
- \\
- \\
-\end{array}$ & $\begin{array}{c}\infty^{6)} \\
\infty^{6)} \\
\infty^{6} \\
239.0^{6)} \\
53.8^{6\}} \\
\infty^{6)} \\
56.4^{6)} \\
68.5^{6)} \\
245^{6)} \\
\infty^{6} \\
106.0^{6)} \\
42.3^{6)} \\
33.0^{6)} \\
56.2^{6)}\end{array}$ & $\begin{array}{c}- \\
- \\
8.2^{\mathrm{a})} \\
\left.10.0^{\mathrm{a}}\right) \\
11.3^{\mathrm{a})} \\
14.7^{\mathrm{a}} \\
15.4^{\mathrm{a})} \\
9.9^{\mathrm{a}} \\
9.6^{\mathrm{a}} \\
10.5^{\mathrm{a})} \\
7.2^{\mathrm{a}} \\
5.8^{\mathrm{a}} \\
7.6^{\mathrm{a})}\end{array}$ \\
\hline Takahashi et al., $(1988,1989)$ & $\begin{array}{l}0.122 \\
0.112 \\
0.103 \\
0.113 \\
0.115 \\
0.117 \\
0.116 \\
\end{array}$ & $\begin{array}{l}1.049 \\
1.143 \\
1.243 \\
1.133 \\
1.113 \\
1.094 \\
1.103 \\
\end{array}$ & $\begin{array}{l}0.106 \\
0.117 \\
0.127 \\
0.116 \\
0.114 \\
0.167 \\
0.224 \\
\end{array}$ & $\begin{array}{l}0.959 \\
1.104 \\
1.188 \\
0.728 \\
0.503 \\
1.020 \\
1.009 \\
\end{array}$ & $\begin{array}{l}1.05 \\
1.14 \\
1.24 \\
1.13 \\
1.11 \\
1.09 \\
1.10 \\
\end{array}$ & $\begin{array}{l}2 \\
2 \\
2 \\
2 \\
2 \\
2 \\
2 \\
\end{array}$ & $\begin{array}{l}351.1 \\
290.6 \\
275.3 \\
356.6 \\
425.1 \\
339.4 \\
372.4 \\
\end{array}$ & $\begin{array}{c}239.0^{6)} \\
53.8^{6)} \\
\infty^{6} \\
56.4^{6)} \\
68.5^{6)} \\
33.0^{6)} \\
56.2^{6)} \\
\end{array}$ & $\begin{array}{c}8.7^{\mathrm{a})} \\
9.2^{\mathrm{a}} \\
12.0^{\mathrm{a})} \\
12.0^{\mathrm{a})} \\
18.2^{\text {a) }} \\
9.5^{\mathrm{a})} \\
8.8^{\mathrm{a}}\end{array}$ \\
\hline Takahashi et al. (1994) & 0.117 & 1.094 & 1.167 & 1.020 & 1.09 & 2 & 339.4 & $38.4^{1)}$ & $8.4^{\mathrm{a})}$ \\
\hline
\end{tabular}

Measuring method of homogenization time -1) colorimetric method combined with visual observation, 2) colorimetric method combined with photoelectric measurements, 3) colorimetric method with video recording, 4) addition of a colored tracer with visual observation, 5) chemical method, 6) method with the use of liquid crystals (dependence of the color of liquid crystals on temperature), 7) method with the use of fluorescence tracers, 8) conductometric method

Measurement of circulation time - a) visualization of the trajectory of suspended particles, b) conductometric method, c) calculated on the basis of measured axial velocities, d) thermal method 


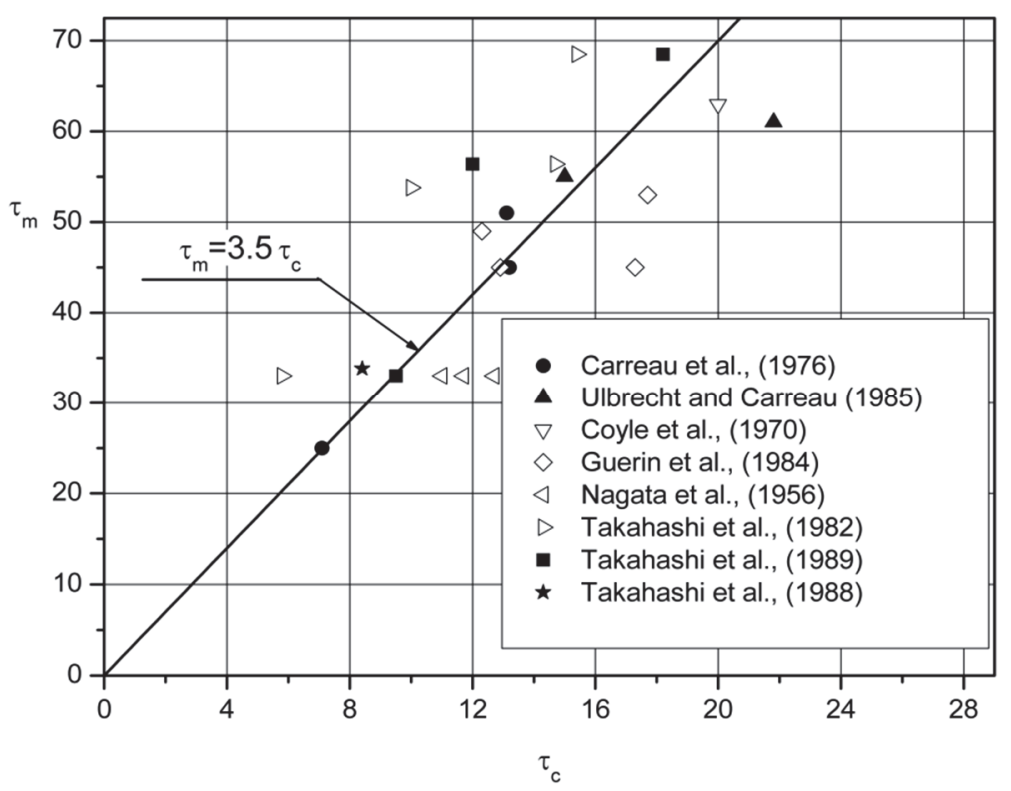

Fig. 1. Dependence of homogenization time on circulation time for ribbon impellers

The scattering of experimental points observed in Fig. 1 is relatively large and is mainly due to different measuring techniques used to determine times $\tau_{m}$ and $\tau_{c}$ and different geometries of the impeller-vessel system. As follows from Fig. 1, the values of $\tau_{m}$ and $\tau_{c}$ are interrelated, but it is difficult to find a precise functional relation between the two variables. It was therefore decided to apply the simplest linear relation (1) which indicates that the liquid contained in the tank can be considered well mixed if each element of the liquid performs 3 or 4 circulation loops in the vessel on average.

$$
\tau_{m}=3.5 \cdot \tau_{c} \pm 16.2 \%
$$

The time average of circulation $\tau_{c}$ can be determined from the secondary circulation $V_{s}$ and volume of the stirred liquid $V$.

$$
\tau_{c}=\frac{V_{s}}{V}
$$

As follows from Table 1, in some studies (Takahashi et al., 1982; Takahashi et al., 1989) the values of $\tau_{m}$ are several times higher than similar values quoted by other authors. In certain cases $\tau_{m} \rightarrow \infty$ which means that in the tank small zones with poorer mixing were observed and in this case only a subjective assessment of the experimenter decided the value of $\tau_{m}$. Therefore, not all data contained in Table 1 have been taken into account in Fig. 1.

In addition to experimental methods used in studies on the hydrodynamics of mixing vessels in a laminar motion, for decades CFD methods have been increasingly applied. They are used to determine the distribution of all hydrodynamic values in the entire volume of the mixing vessel. Noteworthy are the early studies of Thiele (1972) and Ohta et al. (1985) regarding solutions in the 2D space, first solutions of full models in the 3D space proposed by Harvey et al. (1995) and Kaminoyama et al. (1999) and others, or the 3D/2D hybrid model developed by Kuncewicz and Pietrzykowski (2010). The idea of the last model was that a full 3D model was solved in the impeller region and its vicinity, while in the other parts of the vessel a much simpler 2D model was solved. In this way the time needed for model solution was shortened from 7 to 10 times without compromising accuracy of the results.

In our previous work (Kuncewicz et al., 2013) using solutions of a 3D/2D hybrid model we found that for a ribbon impeller with one ribbon its optimal parameters referring to mixing time and mixing power are geometric invariants $d / D=0.92$ and $p / d=1$. 
In this study, using the same 3D/2D model we decided to investigate the effect of two other parameters of the ribbon impeller, i.e. the number of ribbons $N_{R}$ and their widths on the time of homogenization and mixing power and to determine two other optimal parameters of ribbon impellers.

\section{EXPERIMENTAL}

In the experimental part the correctness of the solution of a 3D/2D hybrid model for ribbon impellers equipped with more than one ribbon (Fig. 2) or impellers with reduced ribbon width (Fig. 3) was verified. Figures $2 \mathrm{a}$ and $3 \mathrm{a}$ show a comparison of model distributions of peripheral velocities $u_{\Phi}^{*}$ (solid lines) and axial velocities $u_{z}^{*}$ with their experimental values (points). The experimental values were obtained using a Dantec Laser Doppler Anemometer (LDA). The method of calculating mean velocity values $u_{z}, u_{\phi}$, is given in our previous work (Kuncewicz and Pietrzykowski, 2010).

a)

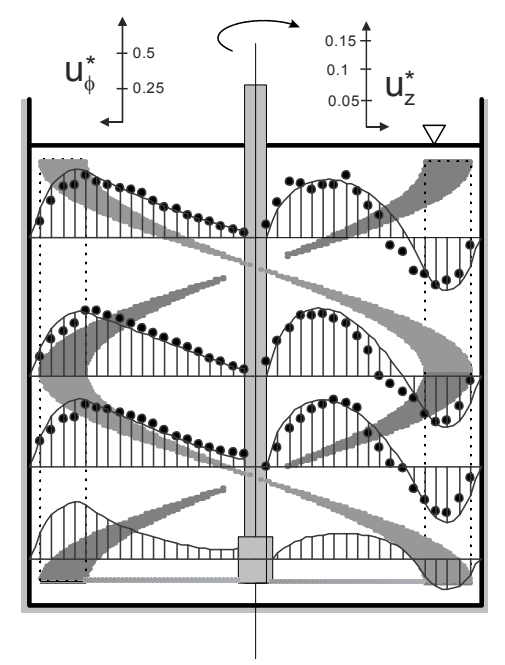

b)

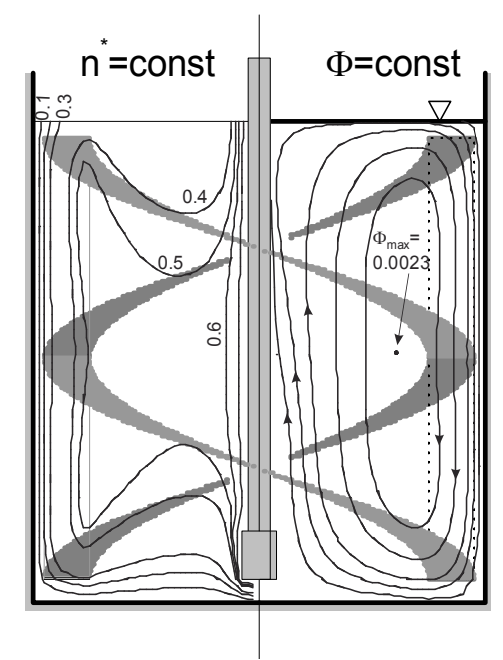

Fig. 2. Model verification (a) and liquid circulation in the tank (b) for $R e=10, d / D=0.92, w / D=0.1, N_{R}=2$

As follows from the analysis of Figs. 2a and b figures, good agreement of both compared values was obtained which indirectly proves the correctness of the model solutions. The highest peripheral velocities were always observed in the case of impeller region, while the greatest axial components occurred not only in the region where liquid was pumped to the bottom of the tank but also in the middle of the tank where the same stream was returning to the liquid level. Comparing results shown in Figs. 2 and 3 it should be noted that for the impeller with two ribbons there was a more than a twofold increase of peripheral circulation $V_{p}$ associated with the impeller rotation. Secondary circulation $V_{s}$, i.e. circulation in the r-z plane also increased. However, that increase was much smaller and amounted to only about $30 \%$. This is due to a maximum value of stream function $\Phi_{\max }$ for both compared impellers. Hence, in this case there was an uneven growth of primary and secondary circulation in the tank and it could be concluded that the increase of the total active surface of the impeller caused first of all an increase of peripheral velocities in the tank. It should also be taken into account that the comparison referred to the impellers with different ribbon widths and their numbers.

Liquid circulation inside the tank is shown in Figs. $2 \mathrm{~b}$ and $3 \mathrm{~b}$. In the middle part of the tank liquid circulates at approximately constant relative peripheral frequency $n=(0.5-0.6) \cdot N$ in the case of a double-ribbon impeller and at frequency $n=(0.35-0.45) \cdot N$ in the impeller with one ribbon. In both cases peripheral velocities were always two or three times higher than axial velocities. In the impeller region, due to the proximity of the tank wall, relative peripheral frequencies $n^{*}$ decrease, although 
taking into account large radius along which the liquid moves in this region its absolute peripheral velocity is the highest.

a)

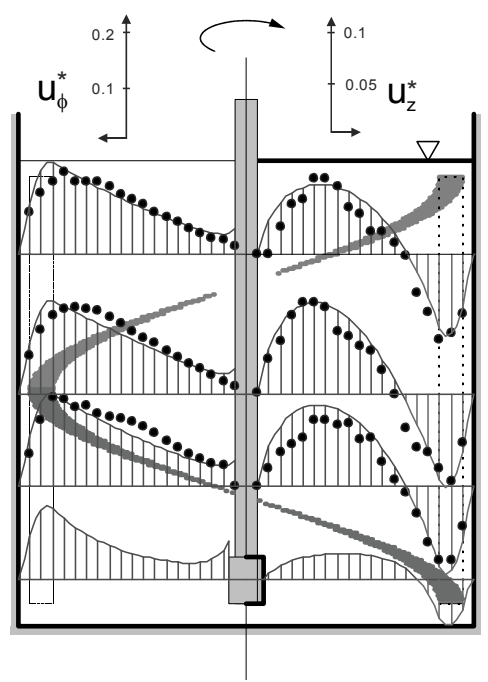

b)

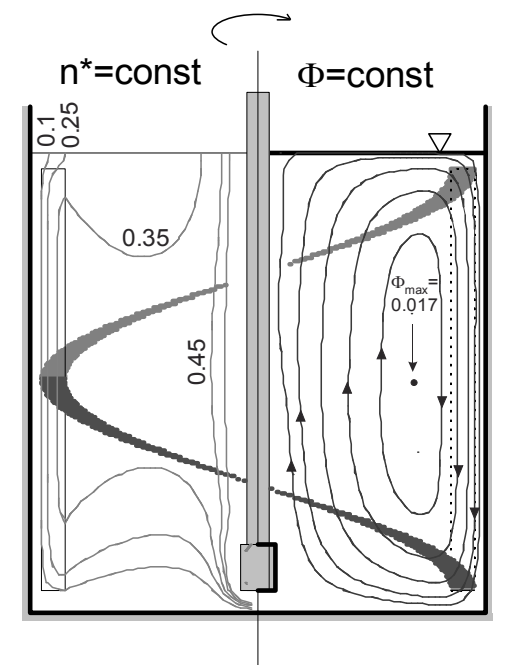

Fig. 3. Model verification (a) and liquid circulation in the tank (b) for $\operatorname{Re}=10, d / D=0.92, p / d=1, w / D=0.075, N_{R}=1$

\section{MODEL CALCULATIONS}

In laminar motion the flow of liquid in the whole tank depends largely on flow in the impeller region. Figure 4 shows model distributions of dimensionless velocity $u_{\phi}^{*}$ for impellers with variable ribbon widths $w$ and their number $N_{R}$, while Fig. 5 presents similar distributions for dimensionless axial velocity $u_{z}^{*}$. As follows from Fig. 4 an increase in the ribbon width and their number causes always an increased peripheral circulation in the impeller region. A fourfold increase in the ribbon width $(w / D=0.05-0.2)$ increases almost twice the maximum liquid velocity $u_{\phi}^{*}$ in the impeller region. Similarly, the number of ribbons has also great impact. A three-ribbon impeller produces primary circulation which is $60 \%$ higher than that of a single-ribbon impeller. In general, it can be concluded that the greater the impeller surface the bigger the liquid stream flowing in the impeller region in the peripheral direction.

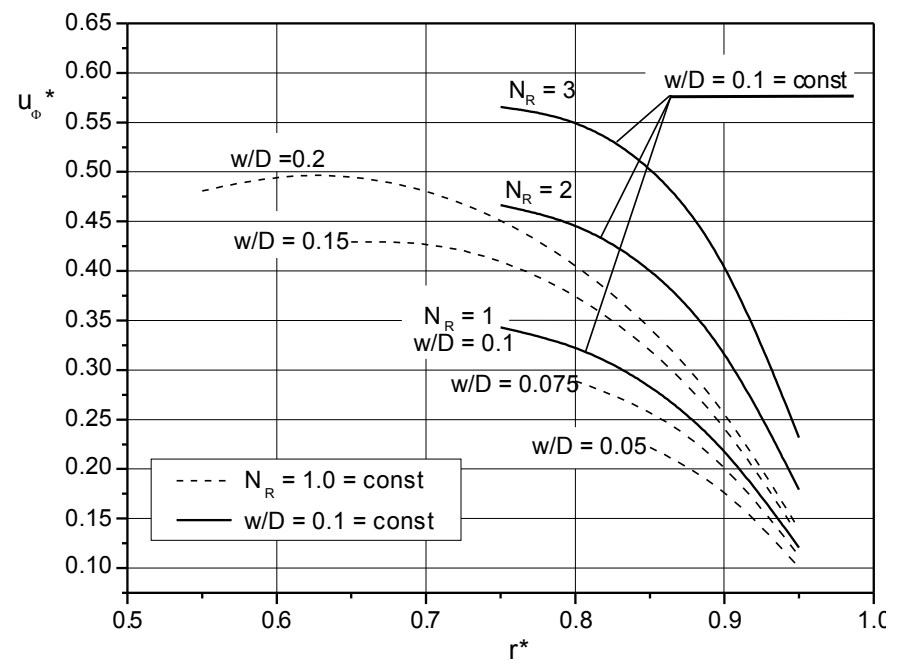

Fig. 4. Liquid flow in the impeller region in peripheral direction for $R e=10, d / D=0.92, p / d=1$ 
On the other hand, an ambiguous impact of the width and number of ribbons on dimensionless axial velocities $u_{z}^{*}$ in the impeller region can be observed when analysing the distributions $u_{z}^{*}=f\left(r^{*}\right)$ in Fig. 5 . Axial velocities $u_{z}^{*}$ increase with an increase of the ribbon width only to the value of $w / D \cong 0.15$. The ribbon of width $w / D=0.2$ has significantly lower axial velocity (the assumed direction of impeller rotations forced liquid flow down the tank, so axial velocities had sign "-"). Thus, excessive increase of the ribbon surface area is not advisable in this case. A similar conclusion can be drawn when analysing distributions $u_{z}^{*}=f\left(r^{*}\right)$ for impellers with different number of ribbons $N_{R}$. In this case the increase of impeller area by adding a second and third ribbon, for the same ribbon width $w / D=0.1$, causes even a decrease of axial velocities in the impeller region. This effect is similar to that observed in the case of the impact of ribbon width on distributions $u_{z}^{*}=f\left(r^{*}\right)$ for $w / D>0.15$. Probably too large active surface area of the ribbons in the mixer causes disturbances in the creation of regular loops inside the vessel.

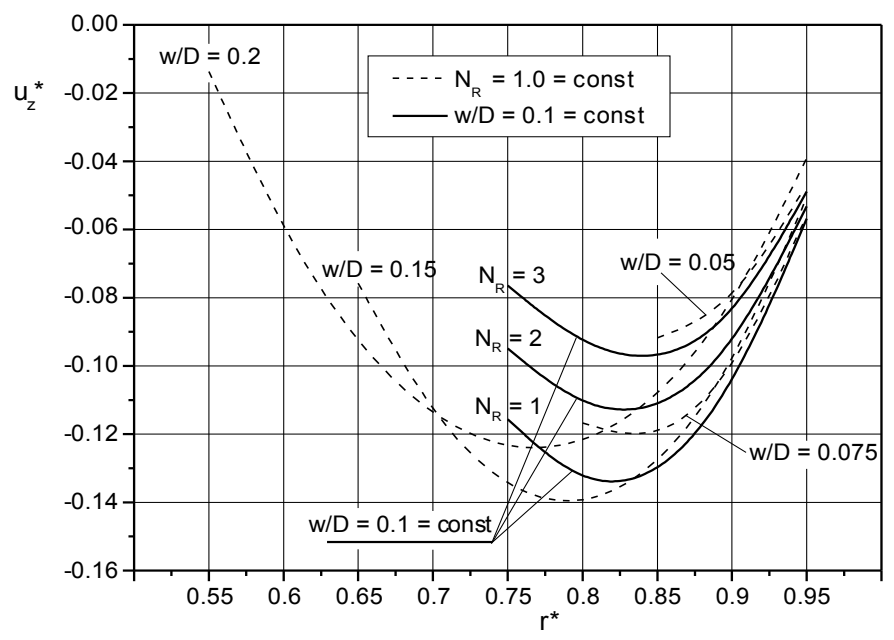

Fig. 5. Liquid flow in the impeller region in axial direction for $R e=10, d / D=0.92, p / d=1$

Peripheral and axial velocities in the impeller region are only part of the whole peripheral and axial circulation in the tank. Therefore having the distributions of all three velocity components in the entire tank (Figs. 2 and 3) one can determine the value of primary circulation $V_{p}$ and secondary circulation $V_{s}$ i.e. the volumetric flow rate of liquid towards the peripheral and radial-axial direction in the whole tank. The values of $V_{p}$ and $V_{s}$ are usually given in the form of dimensionless numbers of primary and secondary circulation $K_{p}$ and $K_{s}$, respectively, defined by Eq. (3).

$$
K_{p}=\frac{V_{p}}{n d^{3}} ; \quad K_{s}=\frac{V_{s}}{N d^{3}}
$$

On the basis of peripheral velocity distributions near the wall and bottom of the vessel obtained from $3 \mathrm{D} / 2 \mathrm{D}$ model solutions it was also possible to determine the mixing power $P$ and then to calculate the dimensionless power number Po and product $\mathrm{Po} \cdot \mathrm{Re}=A$. The value of this product for laminar mixing and for a specified impeller is a constant value independent of the Reynolds number. Functional relations $K_{p}, K_{s}, A=f\left(N_{R}, w / D\right)$ obtained from model solutions are shown in Fig. 6.

The width of ribbons in a moderate way affects the power of mixing. A fourfold increase of the ribbon width caused only about $25 \%$ increase in the mixing power (Fig. 6b). In contrast, the mixing power depended strongly on the number of ribbons. Addition of the second and third ribbon to the singleribbon impeller resulted in an increase of the mixing power by $58 \%$ and $102 \%$, respectively. In both cases the growth of mixing power can be explained by increase in friction resistance that is dominant resistance in the laminar motion. Figure $6 \mathrm{a}$ illustrates the influence of the two analysed parameters on 
the total primary and secondary circulation in the mixer in form of the dimensionless value of $K_{p}$ and $K_{s}$.
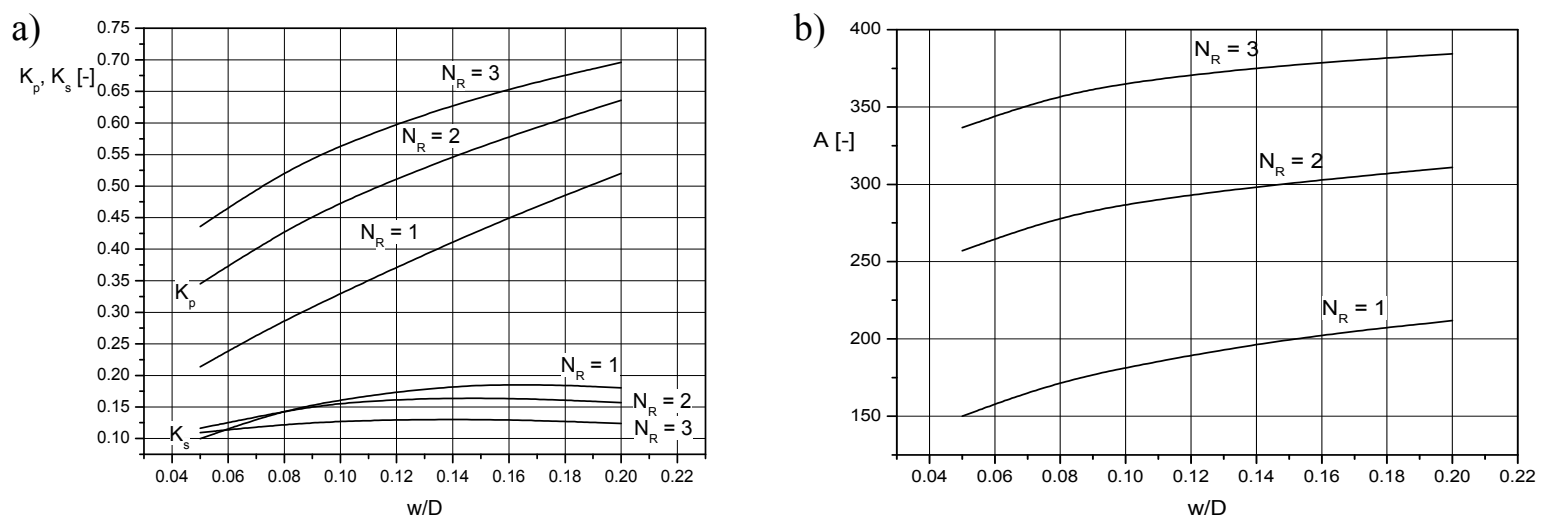

Fig. 6. Primary and secondary circulation in the vessel (a) and the mixing power (b) for

$$
R e=10, d / \mathrm{D}=0.92, p / d=1.0
$$

As follows from analysis of Fig. 6a for ribbon width $w / D=0.1$, addition of the second and third ribbon caused an increase of the primary circulation $K_{p}$ by $44 \%$ and $71 \%$, respectively, while the secondary circulation $K_{s}$ remained virtually unchanged and for $N_{R}=3$ it was even decreased. Hence, the addition of second and third ribbon resulted only in an increase of peripheral circulation which has no effect on circulation time $\tau_{c}$, and consequently on mixing time $\tau_{m}$. The above presented results of mathematical modelling show that additional energy demand needed to drive the second and third ribbon is completely ineffective.

To demonstrate more clearly that addition of the second and third ribbon is pointless one should analyse Table 2 which presents changes in the $K_{p} / K_{s}$ ratio for a different number of ribbons.

Table 2 . The effect of the number of ribbons $N_{R}$ on primary and secondary circulation in the vessel for $w / d=0.1$

\begin{tabular}{|c|c|c|c|c|}
\hline$N_{R}$ & $K_{p}$ & $K_{s}$ & $A$ & $K_{p} / K_{s}$ \\
\hline 1 & 0.330 & 0.162 & 182.0 & 2.03 \\
\hline 2 & 0.476 & 0.159 & 288.2 & 2.99 \\
\hline 3 & 0.567 & 0.128 & 366.0 & 4.42 \\
\hline
\end{tabular}

To fully optimize the ribbon impellers the assumed optimization criterion was the value of $U_{E}$ defined as the amount of energy needed to attain an appropriate mixing degree of liquid unit volume, i.e.

$$
U_{E}=\frac{E}{V}=\frac{P \cdot \tau_{m}}{V} \quad\left[\frac{\mathrm{J}}{\mathrm{m}^{3}}\right]
$$

This method is applied universally and can also be observed in other unit operations of chemical engineering (Obraniak and Gluba, 2012). The value of $U_{E}$ can be determined as a unit mixing energy. Taking into account Eqs. (1) to (3) and Eq. (5) which determine mixing power in the laminar regime

$$
P=A \cdot N^{2} d^{3} \eta \quad[\mathrm{W}]
$$

after simple transformations Eq. (4) will assume the following form

$$
U_{E}=\frac{3.5 \cdot A N \eta}{K_{s}} \quad\left[\frac{\mathrm{J}}{\mathrm{m}^{3}}\right]
$$


The smaller $U_{E}$ the more efficient the impeller. It follows from Eq. (6) that with an increase of the mixing power (constant $A$ from Fig. 6b) and decrease of secondary circulation $\left(K_{S}\right)$, the value of unit mixing energy $U_{E}$ will increase, i.e. mixing efficiency is lower. Such a tendency of changes is largely self-evident. Equation (6) also indicates that the viscosity of the liquid and the impeller rotation have negative impact on the efficiency of the mixing. From the phenomenological point of view the tendency of changes is most understandable. It should be noted that, as follows from Eqs. (3) and (5), rotation frequency of the impeller causes a faster increase of mixing power $P$ than the increase of secondary circulation $V_{s}$ in the vessel $\left(P \propto N^{2}\right.$ and $\left.V_{s} \propto N\right)$. Therefore the value of $N$ is in the numerator and not in the denominator of Eq. (6). A dimensional form of Eq. (6) can be transformed to its dimensionless form $U_{E}^{*}$

$$
U_{E}^{*}=\frac{U_{E}}{n \eta}=\frac{3.5 \cdot A}{K_{s}} \quad[-]
$$

Owing to this the values of $U_{E}{ }^{*}$ can be directly compared for ribbon impellers with different geometric parameters. A comparison is presented in Fig. 7.

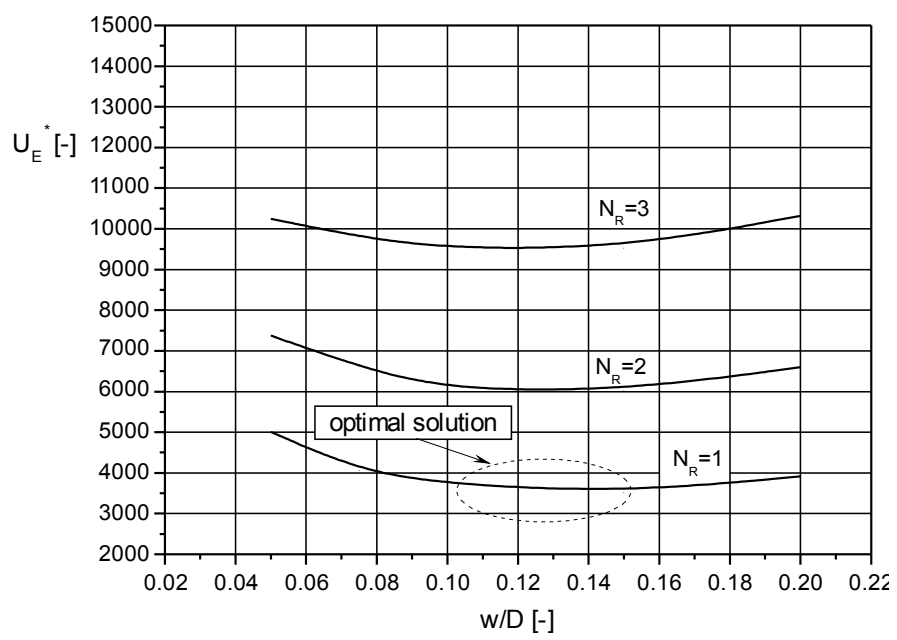

Fig. 7. Dimensionless unit mixing energy for ribbon impellers at $R e=10, p / \mathrm{d}=1.0$ and $d / D=0.92$

As can be seen from Fig. 7 the smallest $U_{E}{ }^{*}$ occurs for a single-ribbon impeller with ribbon width $w / D=0.10$ to 0.15 . Hence, from solutions of the $3 \mathrm{D} / 2 \mathrm{D}$ model it follows that if the main purpose of mixing is to obtain a homogeneous mixture, from the economic point of view the most optimal ribbon impeller is that with the geometric parameters: $d / D=0.92, p / d=1.0, N_{R}=1$ and $w / D=0.10$ to 0.15 . For other purposes than homogenization (e.g. jacketed heat exchange) ribbon impellers with different geometric parameters should be used.

\section{CONCLUSIONS}

- The hybrid 3D/2D model developed in earlier work is also valid for ribbon impellers which have more than one ribbon.

- An increase of the ribbon width has a moderate effect on the growth of mixing power and secondary circulation in the tank, and for $w / D>0.15$ even a decrease in the value of $V_{s}$ occurs.

- A bigger number of ribbons in the tank results only in a significant increase of mixing power and growth of peripheral circulation in the tank. This means that the addition of the second and third ribbon is unprofitable. 
- If the primary purpose of mixing is to achieve short mixing times $\tau_{m}$, from the economic point of view an optimal ribbon impeller operating in laminar regime is the impeller with the following parameters: $d / D=0.92, p / d=1.0, N_{R}=1$ and $w / D=0.10-0.15$.

The research was carried out within grant no. 501/10-34-1-7015

\section{SYMBOLS}

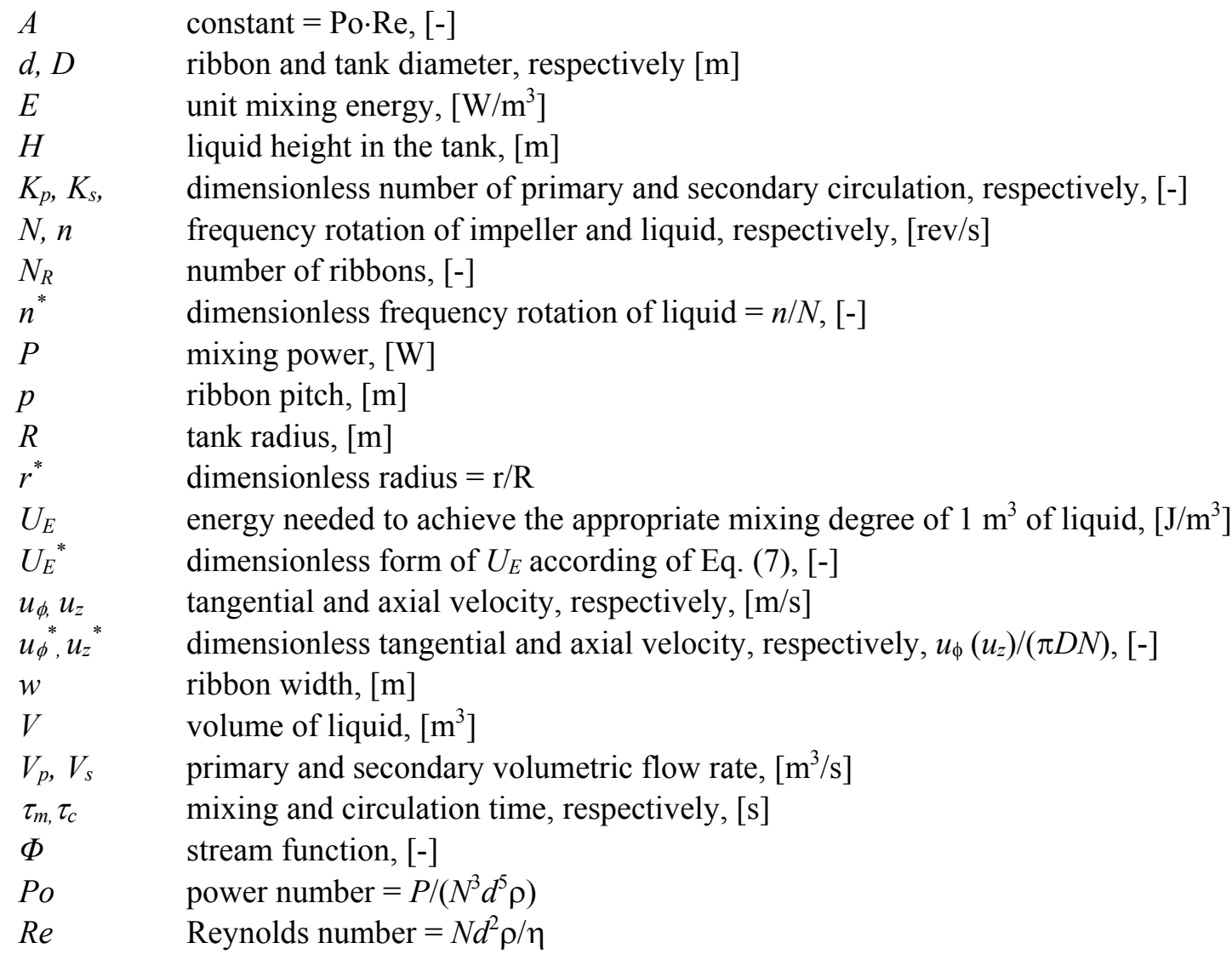

\section{REFERENCES}

Ameur, H., Kamla, Y., Sahel, D., 2017. Performance of helical screw impellers for mixing of viscous liquids in cylindrical reactors. Chemistry Select, 2, 1891-1894. DOI: 10.1002/slct.201602072.

Ameur, H., 2015. Energy efficiency of different impellers in stirred tank reactors. Energy, 93, 1980-1988. DOI: 10.1016/j.energy.2015.10.084.

Anne-Archard D., Marouche M., Boisson H.C., 2006. Hydrodynamics and Metzner-Otto correlation in stirred vessels for yield stress fluids. Chem. Eng. J., 125, 15-24. DOI: 10.1016/j.cej.2006.08.002.

Bakker A., Gates L.E., 1995. Properly choose mechanical agitators for viscous liquids. Chem. Eng. Progress, 91, 25-34.

Carreau P.J., Patterson I., Yap C.Y., 1976. Mixing of viscoelastic fluids with helical-ribbon agitators - I. Mixing time and flow patterns. Can. J. Chem. Eng., 54, 135-142. DOI: 101002/cjce.5450540303.

Coyle C.K., Hirschland H.E., Michel B.J., Oldshue J.Y., 1970. Mixing in viscous liquids. AIChE J., 16, 903-906. DOI: 10.1002/aic.690160608.

Curran S.J., Hayes R.E., Afacan A., Williams M., Tanguy P., 2000. Experimental mixing of a yield stress fluid in a laminar stirred tank. Ind. Eng. Chem. Research, 39, 195-202. DOI: 10.1021/ie990468e. 
Delaplace G., Leuliet J.C., Relandeau V., 2000. Circulation and mixing times for helical ribbon impellers. Review and experiments. Exp. Fluids, 28, 170-182. DOI: 10.1007/s003480050.

Delaplace G., Guerin R., Leuliet J.C., Chhabra R.P., 2006. An analytical model for the prediction of power consumption for shear-thinning fluids with helical ribbon and helical screw ribbon impellers. Chem. Eng. Sci., 61, 3250-3259. DOI: $10.1016 /$ j.ces.2005.11.069.

Gelus M., Le Cardinal G., Germain E., 1979. Choix d'un agitateur lorsque la viscosité varie de 1 centipoise á 2000. Entropie, 88, 54-59.

Guerin P., Carreau P.J., Patterson W.I., Paris J., 1984. Characterization of helical impellers by circulation times. Can. J. Chem. Eng., 62, 301-309. DOI: 10.1002/cjce.5450620302.

Harvey A.D., Lee C.K., Rogers S.E., 1995. Steady-state modeling and experimental measurements of a baffled impeller stirred tank. AIChE J., 41, 2177-2186. DOI: 10.1002/aic.690411002.

He Y., Zhang L., Zhang J., Bao J., 2014a. Helically agitated mixing in dry dilute acid pretreatment enhances the bioconversion of corn stover into ethanol. Biotechnol. Biofuels, 7, 1. DOI: 10.1186/1754-6834-7-1.

He Y., Zhang J. J, Bao J., 2014b. Dry dilute acid pretreatment by co-currently feeding of corn stover feedstock and dilute acid solution without impregnation. Bioresour. Technol., 1, 360-364. DOI: 10.1016/j.biortech.2014.02.074.

Hou W., Zhang L., Zhang, J. Bao J., 2016. Rheology evolution and CFD modeling of lignocellulose biomass during extremely high solids content pretreatment. Biochem. Eng. J., 105, 412-419. DOI: 10.1016/j.bej.2015.10.021.

Kaminoyama M., Watanabe M., Nishi K. and Kamiwano M., 1999. Numerical simulation of local heat transfer coefficient in stirred vessel with impeller for highly viscous fluids. J. Chem. Eng. Japan, 32, 23-30. DOI: $10.1252 /$ jcej.32.23.

Nagata S., Yanagimoto M., Yokoyama T., 1956. Studies on the mixing of high viscous liquids. Memoirs of the Faculty of Engineering, Kyoto University, 18, 444-460.

Kuncewicz Cz., Pietrzykowski M., 2010. A 3D/2D hybrid model for flat blade impellers operating in the laminar flow. Chem. Proc. Eng., 31, 289-302.

Kuncewicz C. 2012. Mieszanie cieczy wysokolepkich. Podstawy procesowe. Wydawnictwo Politechniki Łódzkiej (in Polish).

Kuncewicz Cz. Rieger F., M. Pietrzykowski, J. Stelmach, 2013. 3D/2D hybrid model for ribbon impellers operating in laminar regime. Chem. Eng. Process. Process Intensif., 73, 50-58. DOI: 10.1016/j.cep.2013.08.003.

Liu W., Wang Y.M., Yu Z.C., Bao J., 2012. Simultaneous saccharification and microbial lipid fermentation of corn stover by oleaginous yeast Trichosporon cutaneum. Bioresour. Technol., 118, 13-18. DOI: 10.1016/j.biortech.2012.05.038.

Obraniak A., Gluba T., 2012. Model of energy consumption in the range of nucleation and granule growth in drum granulation bentonite. Physicochemical Problems of Mineral Processing, 48,1, 121-128.

Ohta M., Kuriyama M., Arai K., Saito S., 1985. A two-dimensional model for the secondary flow in an agitated vessel with anchor impeller. J. Chem. Eng. Japan, 18, 81-84. DOI: 10.1252/jcej.18.81.

Rieger F., Novak V., Havelkova D., 1986. Homogenization efficiency of helical ribbon agitators. Chem. Eng. J., 33, 143-150. DOI: 10.1016/0300-9467(86)80013-2.

Robinson M., Cleary P.W., 2012. Flow and mixing performance in helical ribbon mixers. Chem. Eng. Sci., 84, 382-398. DOI: 10.1016/j.ces.2012.08.044.

Shiue S.J., Wong C.W., 1984. Studies on homogenization efficiency of various agitators in liquid blending. Can J. Chem. Eng., 62, 602-609. DOI: 10.1002/cjce.5450620505.

Soliman M.G., 1985. Agitation de fluides visqueux pseudoplastiques par un double ruban helicoïdal. Thesis, I.N.P. Toulouse, France.

Stręk F., 1981. Mieszanie i mieszalniki. WNT Warszawa.

Takahashi K., Sasaki M., Arai K., 1982. Effects of geometrical variables of helical ribbon impellers on mixing of highly viscous Newtonian liquids. J. Chem. Eng. Japan, 15, 217-224. DOI: 10.1252/jcej.15.217.

Takahashi K., Yokota T., Konno H.,1988. Mixing of pseudoplastic liquid in a equipped with a variety of helical ribbon impellers. J. Chem. Eng. Japan, 21, 63-68. DOI: 10.1252/jcej.21.63.

Takahashi K., Iwaki M., Yokota T., Konno H., 1989. Circulation time for pseudoplastic liquids in a vessel equipped with a variety of helical ribbon impellers. J. Chem. Eng. Japan, 22, 413-418. 10.1252/jcej.22.413.

Takahashi K., Yokota T., Furukawa T., Harada K., 1994. Mixing of highly viscous newtonian liquid in a helical ribbon agitated vessel at various liquid depths. J. Chem. Eng. Japan, 27, 244-247. DOI: 10.1252/jcej.27.244. 
Takahashi K., Sugawara N., Takahata Y., 2015. Mixing time in an agitated vessel equipped with large impeller. J. Chem. Eng. Japan, 48, 513-517. DOI: 10.1252/jcej.14we192.

Thiele H., 1972. Strömmung und Leistungbedarf beim Rühren Newtonscher Flüssigkeiten mit Anker, Blatt-und Turbinenrühren in laminar Bereich. Dissertation, Technische Universität Berlin.

Ulbrecht J., Carreau P., 1985. Mixing of Liquids by Mechanical Agitation, Chapter 4. Gordon and Breach, New York.

Wang Xiao, Fradette L., Takenaka K., Tanguy Ph., 2012. Effect of operating parameters on the mixing performance of the superblend coaxial mixer. Ind. Eng. Chem. Research, 51, 1826-1833. DOI: $10.1021 / \mathrm{ie} 200707 \mathrm{n}$.

Wu B.X., 2012. CFD simulation of mixing for high-solids anaerobic digestion. Biotechnol. Bioeng., 109, 2116-2126. DOI: 10.1002/bit.24482.

Zhang J., Chu D.Q., Huang J., Yu Z.C., Dai G.C., Bao J., 2010. Simultaneous saccharification and ethanol fermentation at high corn stover solids loading in a helical stirring bioreactor. Biotechnol. Bioeng., 105, 718-728. DOI: 10.1002/bit.2259.

Zhang L., Zhang J., Li C., Bao J., 2014. Rheological characterization and CFD modelling of corn stover-water mixing system at high solids loading for dilute acid pretreatment. Biochem. Eng. J., 90, 324-332. DOI: 10.1016/j.bej.2014.06.018.

Zhao K., Qiao Q.A., Chu D.Q., Gu H.Q., Dao T.H., Zhang J., Bao J., 2013. Simultaneous saccharification and high titer lactic acid fermentation of corn stover using a newly isolated lactic acid bacterium Pediococcus acidilactici DQ2. Bioresour. Technol., 135, 481-489. DOI: 10.1016/j.biortech.2012.09.063.

Received 27 October 2016

Received in revised form 21 August 2017

Accepted 04 September 2017 